\title{
Arus lagrangian di sekitar rumpon di tengah teluk Manado
}

\author{
Flow of lagrangian around fads of Manado bay centre \\ Demsi Yunaldo Tatanging, Alfret Luasunaung, Vivanda O. J. Modaso, Patrice N. I. Kalangi, \\ KAWILARANG W. A. MASENGI dan HENRY J. KUMAJAS ${ }^{\dagger}$ \\ Program Studi Pemanfaatan Sumberdaya Perikanan, Fakultas Perikanan dan Ilmu Kelautan, \\ Universitas Sam Ratulangi, Manado 95115
}

\begin{abstract}
Traditional fisheries communities in Manado Bay utilize the potensi of fisheries resources through fishing activities using simple gear and raft as fish aggregating device (FAD). Raft shift is affected by surface currents. The Objective of the study was to examine the current patterns around the raft in Manado Bay (124 47'42.5" E; 01 30'22" N) using Lagrangian Method. The Study was based on descriptive method float tracking for data collection and carried out for one month. Mapping and data analyses of the current patterns used numerical computation software. Results showed the raft was dominated by currents towards the east, the north and the south affected by tidal conditions.
\end{abstract}

Keywords: FADs, surface currents, lagrangian, numerical computation

\begin{abstract}
ABSTRAK
Masyarakat nelayan tradisional di daerah Teluk Manado memanfaatkan potensi sumber daya perikanan melalui usaha penangkapan ikan dengan menggunakan peralatan relatif sederhana dan menggunakan alat bantu rumpon. Pergerakan atau perpindahan rumpon sangat di pengaruhi oleh arus permukaan. Untuk itu, tujuan penelitian adalah mengetahui pergerakan dan pola arus yang ada di sekitar rumpon di tengah teluk Manado (124 47'42.5" BT; 01 30'22.0” LU) dengan menggunakan Metode Lagrangian. Penelitian ini berdasarkan metode deskriptif dengan teknik pengumpulan data menggunakan float tracking dan dilaksanakan selama sebulan. Pemetaan dan analisis data pola pergerakan arus dilakukan dengan menggunakan perangkat lunak komputasi numerikal. Hasil penelitian menunjukkan, arus permukaan di sekitar rumpon didominsasi pergerakan dan pola arus ke arah Timur, Utara dan Selatan dipengaruhi oleh pasang surut.
\end{abstract}

Kata-kata kunci: rumpon, arus permukaan, lagrangian, komputasi numerikal

\section{PENDAHULUAN}

Indonesia merupakan negara kepulauan yang memiliki lautan yang sangat luas dan kaya akan sumber daya alam dan sumber daya hayati. Perairan Teluk Manado merupakan salah satu kawasan perairan di Sulawesi utara yang memiliki sumber daya perikanan yang potensial dengan keanekaragaman jenis ikan yang tinggi. Masyarakat nelayan tradisional di daerah Teluk Manado memanfaatkan potensi sumber daya perikanan tersebut melalui usaha penangkapan ikan dengan menggunakan peralatan relatif sederhana dan menggunakan alat bantu rumpon. Pergerakan atau perpindahan rumpon sangat dipengaruhi oleh arus permukaan, karena arus merupakan salah satu faktor oseanografi yang sangat menarik untuk dikaji terutama dalam menghasilkan informasi hidrografi yang bertujuan untuk kegiatan navigasi dan keselamatan pelayaran, penetapan batas wilayah atau daerah di laut, studi dinamika pesisir dan pengelolaan sumber daya laut.

Pengertian arus adalah gerakan air yang dilakukan oleh perpindahan berkala (Nybakken, 1992) dan pengukuran arus telah dilakukan sejak dahulu dengan beberapa metode secara langsung yaitu data kecepatan dan arah arus langsung ditampilkan oleh alat-alat pengukur arus yang digunakan, maupun secara tidak langsung yaitu

\footnotetext{
*Penulis untuk penyuratan; email: dtatanging@yahoo.com
} 
dengan memanfaatkan peranan suhu, salinitas, tekanan dan gradien potensial listrik didalam lautan (Stowe, 1987). Untuk mengamati arus permukaan dapat di gunakan Metode Lagrangian dengan pengamatan gerakan arus permukaan dari satu titik ke titik berikutnya dalam rentang waktu tertentu (Poerbandono dan Djunasjah, 2005). Metode ini dilakukan dengan memperhitungkan jalur yang dilalui oleh setiap partikel fluida yang dinyatakan sebagai fungsi dari waktu sebagai acuan penentuan arah dan laju suatu fluida (Pickard dan Emery, 1990; Gross, 1990). Teknik ini sudah digunakan untuk mempelajari kecepatan arus di muara sungai Porong, Kabupaten Pasuruan (Warsito, 2011) selanjutnya Kamat $d k k$, 2014; Kalangi dan Budiman (2000) menggunakan Metode Lagrangian untuk mendeskripsikan kondisi arus permukaan di tengah perairan Teluk Manado dan pantai Tanjung Kelapa Kecamatan Tombariri Minahasa. Penelitian ini bertujuan mengetahui pergerakan dan pola arus yang ada di sekitar rumpon di tengah Teluk Manado (124 $\left.47 \begin{array}{lllllll}42,5 & \text { BT } & 01 & 30 & 22,0 & \text { LU }\end{array}\right)$ dengan menggunakan Metode Lagrangian. Hasil penelitian ini diharapkan akan dapat memberikan informasi ilmiah yang bermanfaat, sebagai salah satu bahan pertimbangan dalam menentukan kebijakan pengembangan teknologi pemanfaatan sumber daya perikanan terutama mengenai pergerakan arus di sekitar rumpon di tengah teluk Manado

\section{METODE PENELITIAN}

Penelitian ini berdasarkan metode deskriptif, bertujuan untuk memberikan atau menjabarkan suatu keadaan atau fenomena yang terjadi saat ini dengan menggunakan prosedur ilmiah untuk menjawab masalah secara aktual (Sugiyono, 2011). Teknik pengumpulan data untuk mendekati tujuan penelitian, dilakukan pengukuran arus dengan Metode Lagrangian (Float Tracking). Prinsip kerja Metode Lagrangian berdasarkan pada pergerakan tiga pelampung arus di permukaan laut kemudian setiap pelampung diambil posisinya menggunakan Garmin GPS Map 76CSx setiap satu jam. Pengambilan posisi dari ke tiga pelampung tersebut dilakukan sampai sepuluh kali. Pengambilan data dilakukan dalam periode empat minggu, masingmasing 4 hari pada minggu 1, 2 dan 4 dan 3 hari pada minggu ke 3 . Pola pengambilan data ini lakukan untuk melihat arah yang lebih dominan dari pelampung arus. Data posisi dalam memori GPS selanjutnya disalin ke tabel data pada program komputer Microsoft Excel. Kemudian posisi-posisi ini dipetakan dalam peta lokasi penelitian berdasarkan waktu pengukuran untuk melihat perpindahan pelampung-pelampung arus. Berdasarkan data ini, dibuat peta pola pergerakan arus. Pemetaan dan analisis pola pergerakan arus dilakukan dengan menggunakan perangkat lunak komputasi numerikal.

\section{HASIL DAN PEMBAHASAN}

\section{Hasil}

Berdasarkan penelitian pada minggu pertama (Tabel 1, Gambar 1), pola pergerakan arus yang terjadi sangat jauh perpindahannya dari titik semula. Ketiga pelampung jauh bergerak dari sekitar rumpon, mengarah ke darat dan menyusur tepian pantai Malalayang sampai di depan mulut Sungai Bahu.

Pada pada minggu kedua (Tabel 2, Gambar 2), pola pergerakan arus bergerak sangat jauh dari posisi awal. Awalnya tiga pelampung awalnya bergerak ke arah Tanjung Pisok kemudian bergerak jauh ke arah Pulau Bunaken.

Pada minggu ketiga (Tabel 3, Gambar 3), pola pergerakan arus bergerak tidak jauh dari sekitar rumpon, dari posisi awal sampai akhir pengamatan posisi pelampung selalu berdekatan.

Pada minggu keempat (Tabel 4, Gambar 4), pola pergerakan arus yang terjadi cukup cepat. Tiga pelampung bergerak jauh dari sekitar rumpon, posisi awal pelampung. Selanjutnya ketiga pelampung bersamaan bergerak ke arah timur.

\section{Pembahasan}

Dilihat dari hasil penelitian pergerakan pola arus yang ada disekitar rumpon di Teluk Manado yang di ukur menggunakan metode Lagrangian pergerakan massa air sangat bervariasi tiap harinya. Massa air kadang-kadang berpindah jauh dari sekitar rumpon dan kadang-kadang berpindah hanya disekitar rumpon. Hal ini disebabkan berbagai faktor, yaitu pasang surut air laut dan keadaan cuaca. Kondisi arus di sekitar rumpon di tengah Teluk Manado didominasi arus ke arah timur, utara dan selatan. Berdasarkan pengamatan, apabila tinggi pasang surut air laut kecil, pergerakan arus sangat lambat dan posisi ketiga pelampung tersebut selalu berada tidak jauh dari rumpon. Apabila tinggi pasang surut air laut besar, pergerakan arus akan berubah menjadi lebih cepat dan bergerak jauh dari sekitar rumpon. 
Tabel 1. data posisi pelampung arus yang sudah disertakan dengan nomor pelampung dan waktu pengambilan posisi pelampung pada minggu pertama.

\begin{tabular}{|c|c|c|c|c|}
\hline LINTANG UTARA & BUJUR TIMUR & No PELAMPUNG & JAM & MENIT \\
\hline 1.49665 & 124.7925 & 3 & 9 & 59 \\
\hline 1.4968 & 124.7925 & 1 & 10 & 0 \\
\hline 1.496483 & 124.7924 & 2 & 10 & 0 \\
\hline 1.484833 & 124.7926 & 3 & 11 & 3 \\
\hline 1.485133 & 124.7925 & 1 & 11 & 4 \\
\hline 1.484783 & 124.7927 & 2 & 11 & 5 \\
\hline 1.476567 & 124.7958 & 3 & 11 & 56 \\
\hline 1.476683 & 124.7951 & 1 & 11 & 58 \\
\hline 1.47635 & 124.7957 & 2 & 11 & 59 \\
\hline 1.468767 & 124.8014 & 3 & 12 & 57 \\
\hline 1.468433 & 124.8002 & 1 & 12 & 59 \\
\hline 1.468083 & 124.801 & 2 & 13 & 0 \\
\hline 1.4662 & 124.8056 & 3 & 13 & 57 \\
\hline 1.466133 & 124.8037 & 1 & 13 & 58 \\
\hline 1.4656 & 124.8046 & 2 & 13 & 59 \\
\hline 1.465683 & 124.8104 & 3 & 14 & 58 \\
\hline 1.465 & 124.8084 & 1 & 15 & 1 \\
\hline 1.465267 & 124.8092 & 2 & 15 & 2 \\
\hline 1.464083 & 124.8152 & 3 & 15 & 55 \\
\hline 1.464033 & 124.812 & 1 & 15 & 57 \\
\hline 1.464367 & 124.8131 & 2 & 15 & 59 \\
\hline 1.46485 & 124.8182 & 3 & 16 & 53 \\
\hline 1.465917 & 124.8156 & 1 & 16 & 55 \\
\hline 1.4665 & 124.8178 & 2 & 16 & 56 \\
\hline 1.467583 & 124.8195 & 3 & 17 & 55 \\
\hline 1.4697 & 124.8194 & 1 & 17 & 56 \\
\hline 1.469167 & 124.8206 & 2 & 17 & 57 \\
\hline 1.469717 & 124.82 & 3 & 18 & 47 \\
\hline 1.472317 & 124.8212 & 1 & 18 & 49 \\
\hline
\end{tabular}

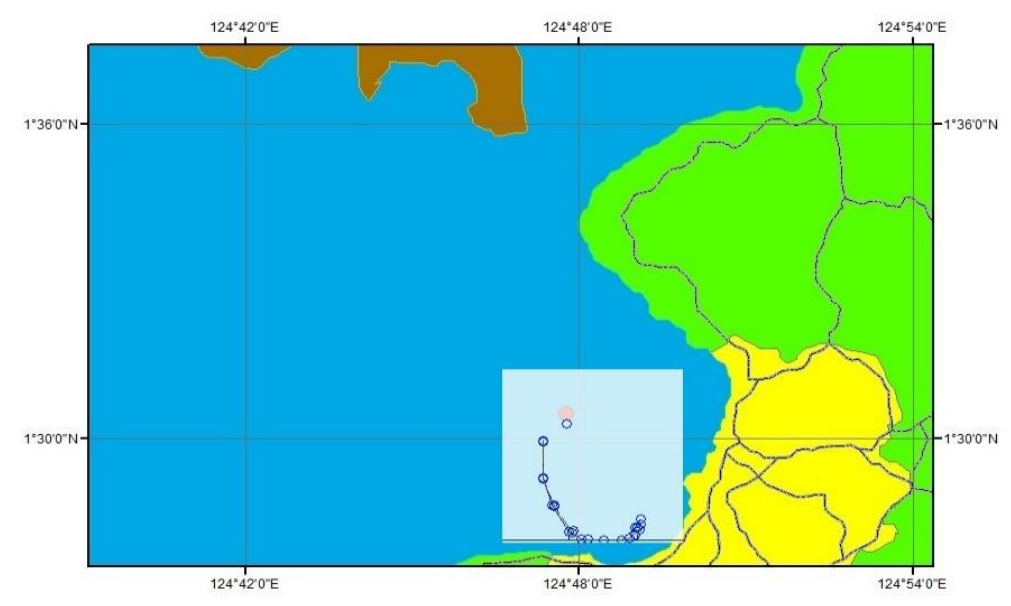

Gambar 1. Pola pergerakan arus di minggu pertama 
Tabel 2. data posisi pelampung arus yang sudah disertakan dengan nomor pelampung dan waktu pengambilan posisi pelampung pada minggu kedua.

\begin{tabular}{|c|c|c|c|c|}
\hline LINTANG UTARA & BUJUR TIMUR & No. PELAMPUNG & JAM & MENIT \\
\hline 1.510194 & 124.7930 & 1 & 9 & 49 \\
\hline 1.510389 & 124.7931 & 2 & 9 & 49 \\
\hline 1.510583 & 124.7933 & 3 & 9 & 50 \\
\hline 1.516806 & 124.8026 & 1 & 10 & 46 \\
\hline 1.516861 & 124.8027 & 3 & 10 & 46 \\
\hline 1.516889 & 124.8027 & 2 & 10 & 47 \\
\hline 1.522139 & 124.8046 & 1 & 11 & 46 \\
\hline 1.522306 & 124.8047 & 3 & 11 & 46 \\
\hline 1.522417 & 124.8048 & 2 & 11 & 47 \\
\hline 1.524778 & 124.8075 & 3 & 12 & 39 \\
\hline 1.525167 & 124.8076 & 1 & 12 & 40 \\
\hline 1.525833 & 124.8079 & 2 & 12 & 40 \\
\hline 1.531667 & 124.8092 & 2 & 13 & 45 \\
\hline 1.531556 & 124.8091 & 1 & 13 & 47 \\
\hline 1.5315 & 124.8091 & 3 & 13 & 48 \\
\hline 1.542833 & 124.8026 & 3 & 14 & 53 \\
\hline 1.543083 & 124.8024 & 1 & 14 & 56 \\
\hline 1.543556 & 124.8022 & 2 & 14 & 57 \\
\hline 0.055583 & 124.7956 & 3 & 15 & 49 \\
\hline 1.556778 & 124.795 & 1 & 15 & 50 \\
\hline 1.557417 & 124.7948 & 2 & 15 & 51 \\
\hline 1.563861 & 124.7917 & 3 & 16 & 50 \\
\hline 1.564417 & 124.7919 & 1 & 16 & 51 \\
\hline 1.565389 & 124.7921 & 2 & 17 & 53 \\
\hline 1.570167 & 124.7937 & 2 & 17 & 53 \\
\hline 1.568694 & 124.7924 & 3 & 17 & 55 \\
\hline 1.56925 & 124.793 & 1 & 17 & 56 \\
\hline 1.575083 & 124.795 & 3 & 18 & 21 \\
\hline 1.576417 & 124.7958 & 1 & & \\
\hline 1.578417 & 124.7976 & 2 & & \\
\hline
\end{tabular}

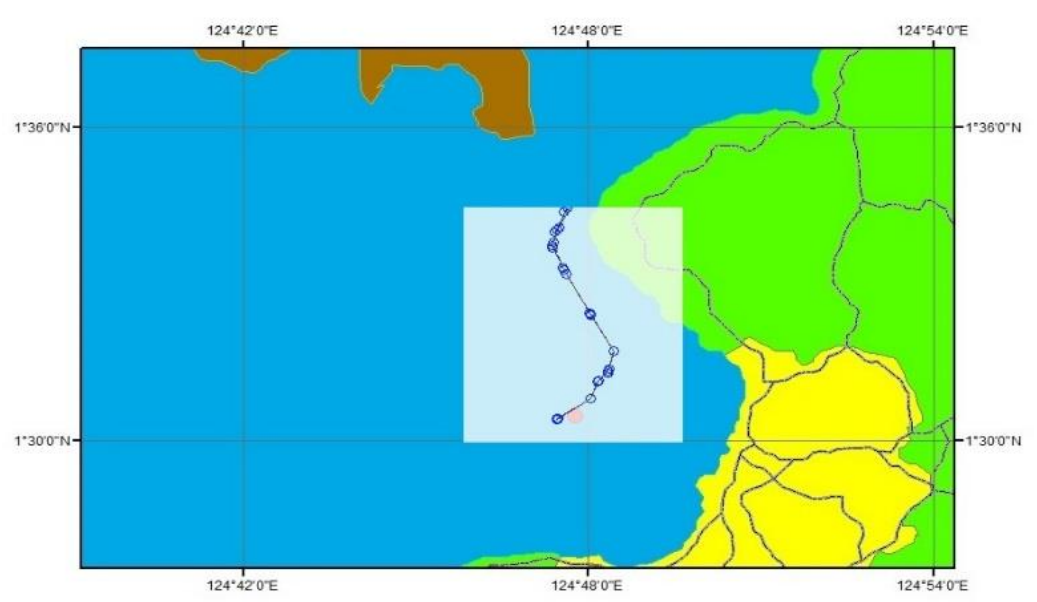

Gambar 2. Pola pergerakan arus di minggu kedua 
D. Y. Tatanging dkk.

Tabel 3. data posisi pelampung arus yang sudah disertakan dengan nomor pelampung dan waktu pengambilan posisi pelampung pada minggu ketiga.

\begin{tabular}{|c|c|c|c|c|}
\hline LINTANG UTARA & BUJUR TIMUR & No. PELAMPUNG & JAM & MENIT \\
\hline 1.508583 & 124.794 & 2 & 8 & 51 \\
\hline 1.508917 & 124.7936 & 3 & 9 & 57 \\
\hline 1.508972 & 124.7933 & 1 & 9 & 58 \\
\hline 1.51375 & 124.7942 & 3 & 9 & 58 \\
\hline 1.512944 & 124.7943 & 1 & 9 & 58 \\
\hline 1.513611 & 124.7949 & 2 & 10 & 57 \\
\hline 1.515083 & 124.7871 & 2 & 10 & 57 \\
\hline 1.515639 & 124.7863 & 3 & 10 & 59 \\
\hline 1.515639 & 124.7863 & 1 & 11 & 56 \\
\hline 1.516833 & 124.78 & 2 & 11 & 57 \\
\hline 1.517361 & 124.7796 & 1 & 11 & 58 \\
\hline 1.517278 & 124.7793 & 3 & 12 & 53 \\
\hline 1.518417 & 124.7743 & 2 & 12 & 55 \\
\hline 1.518833 & 124.7738 & 1 & 12 & 55 \\
\hline 1.518111 & 124.774 & 3 & 13 & 58 \\
\hline 1.509889 & 124.7741 & 3 & 13 & 59 \\
\hline 1.510583 & 124.7741 & 2 & 13 & 59 \\
\hline 1.511278 & 124.7737 & 1 & 14 & 57 \\
\hline 1.504472 & 124.7768 & 3 & 14 & 58 \\
\hline 1.506389 & 124.7757 & 2 & 14 & 59 \\
\hline 1.506694 & 124.7747 & 1 & 15 & 59 \\
\hline 1.504194 & 124.7763 & 3 & 15 & 59 \\
\hline 1.505639 & 124.7748 & 2 & 16 & 1 \\
\hline 1.506056 & 124.7732 & 1 & 17 & 1 \\
\hline 1.502333 & 124.7748 & 3 & 17 & 1 \\
\hline 1.503917 & 124.7731 & 2 & 17 & 2 \\
\hline 1.504528 & 124.7715 & 1 & 17 & 59 \\
\hline 1.500806 & 124.7734 & 2 & 17 & 59 \\
\hline 1.501333 & 124.7717 & 1 & 17 & 59 \\
\hline 1.498889 & 124.7755 & 3 & 18 & 30 \\
\hline
\end{tabular}

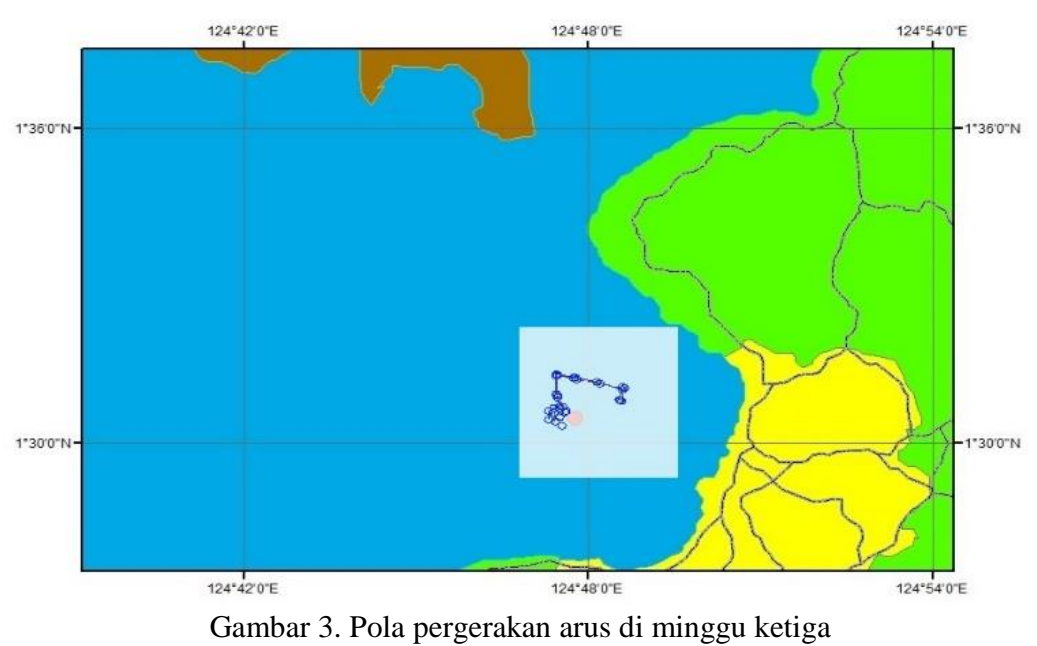


Tabel 4. data posisi pelampung arus yang sudah disertakan dengan nomor pelampung dan waktu pengambilan posisi pelampung pada minggu keempat.

\begin{tabular}{|c|c|c|c|c|}
\hline LINTANG UTARA & BUJUR TIMUR & No. PELAMPUNG & JAM & MENIT \\
\hline 1.50335 & 124.7919 & 1 & 9 & 34 \\
\hline 1.50335 & 124.7919 & 2 & 9 & 34 \\
\hline 1.50335 & 124.7919 & 3 & 9 & 34 \\
\hline 1.507367 & 124.7851 & 1 & 10 & 28 \\
\hline 1.507367 & 124.7851 & 2 & 10 & 28 \\
\hline 1.507633 & 124.785 & 3 & 10 & 29 \\
\hline 1.512567 & 124.781 & 1 & 11 & 35 \\
\hline 1.512767 & 124.7807 & 2 & 11 & 36 \\
\hline 1.512767 & 124.7807 & 3 & 11 & 36 \\
\hline 1.517667 & 124.7737 & 1 & 12 & 36 \\
\hline 1.51775 & 124.7731 & 2 & 12 & 37 \\
\hline 1.517783 & 124.7728 & 3 & 12 & 38 \\
\hline 1.517583 & 124.7645 & 1 & 13 & 36 \\
\hline 1.517483 & 124.7638 & 2 & 13 & 37 \\
\hline 1.517433 & 124.7634 & 3 & 13 & 38 \\
\hline 1.515133 & 124.7581 & 1 & 14 & 34 \\
\hline 1.51525 & 124.7575 & 2 & 14 & 35 \\
\hline 1.51525 & 124.7575 & 3 & 14 & 35 \\
\hline 1.51385 & 124.7578 & 1 & 15 & 27 \\
\hline 1.513983 & 124.7573 & 2 & 15 & 28 \\
\hline 1.514117 & 124.7571 & 3 & 15 & 28 \\
\hline 1.5105 & 124.7556 & 1 & 16 & 32 \\
\hline 1.510483 & 124.755 & 2 & 16 & 33 \\
\hline 1.51055 & 124.7548 & 3 & 16 & 33 \\
\hline 1.504517 & 124.7523 & 3 & 17 & 23 \\
\hline 1.5043 & 124.7524 & 2 & 17 & 24 \\
\hline 1.5039 & 124.7525 & 1 & 17 & 24 \\
\hline 1.499283 & 124.7515 & 3 & 18 & 6 \\
\hline 1.498783 & 124.7516 & 2 & 18 & 7 \\
\hline 1.498133 & 124.7516 & 1 & 18 & 8 \\
\hline
\end{tabular}

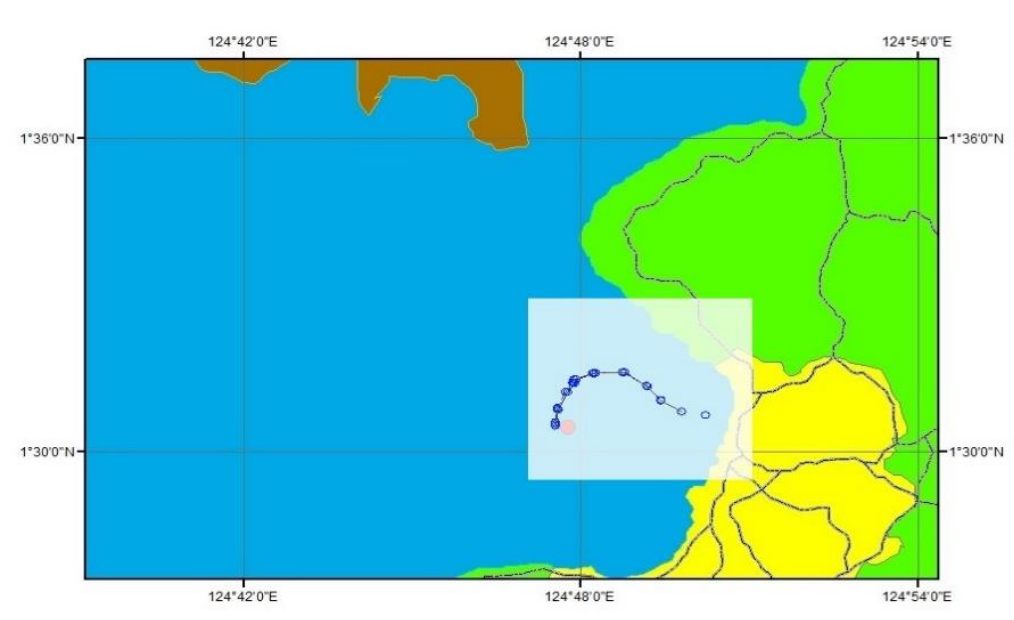

Gambar 4. Pola pergerakan arus di minggu keempat 


\section{KESIMPULAN}

Pola pergerakan arus di sekitar rumpon di tengah Teluk Manado yang diamati dengan Metode Lagrangian selama satu bulan penelitian, dominan ke arah timur, utara dan selatan yang dipengaruhi oleh tinggi rendahnya pasang surut.

\section{Acknowledgement}

Penelitian ini merupakan bagian dari penelitian yang dibiayai oleh Direktorat Riset dan Pengabdian Masyrakat, Dirjen Penguatan Riset dan Pengembangan Kemristekdikti Tahun 2017.

\section{DAFTAR PUSTAKA}

Gross, M. G. 1990. Oceanography. ed. 6th. Macmillan Publishing Company, New York.
Nybaken, J. W. 1992. Biologi Laut Suatu Pendekatan Ekologi. PT. Gramedia.Jakarta.

Kamat, Y. N., P. N. I. Kalangi dan M. S. Sompie. 2014. Pola Arus Permukaan Saat Surut Di Sekitar Muara Sungai Malalayang, Teluk Manado. Jurnal Ilmu dan Teknologi Perikanan Tangkap 1(Edisi Khusus November): 99-104.

Pickard, G. L. dan W. J. Emery. 1990. Descriptive Physical Oceanography: An Introduction. Pergamon Press, Oxford.

Poerbandono dan E. Djunarsjah. 2005. Survei Hidrografi. Refika Aditama, Bandung, 166 pp.

Kalangi, P. N. I dan J. Budiman.2000. Arus Permukaan Di Perairan PantaiTanjung Kelapa Kecamatan Tombariti Minahasa. Jurnal Fakultas Perikanan Unsrat. II(1):29-33

Sugiyono. 2011. Metode Penelitian Pendidikan Pendekatan Kuantitatif, Kualitatif, dan R\&D. Bandung.

Stowe, K. 1987. Essentials of Ocean Ccience. New York.

Warsito, A. 2011. Studi penyebaran sedimen tersuspensi di muara sungai Porong, Kabupaten Pasuruan. Buletin Oseanografi Marina 1(2): 60-81. 